\title{
Efeito do Corte da Parte Aérea na Sobrevivência do Marmeleiro (Croton Sonderianus Muell.Arg.) ${ }^{1}$
}

\section{Fabianno Cavalcante de Carvalho², João Ambrósio de Araújo Filho ${ }^{3}$, Rasmo Garcia ${ }^{4}$, José Morais Pereira Filho ${ }^{5}$, Vanda Moreira de Albuquerque ${ }^{6}$}

\begin{abstract}
RESUMO - O trabalho foi conduzido na Embrapa Caprinos, em Sobral, Ceará, com o objetivo de avaliar os efeitos do corte da parte aérea em relação à altura da rebrota na sobrevivência, persistência e no vigor da rebrota do marmeleiro e produção subseqüente de fitomassa do estrato herbáceo. O corte das plantas foi realizado a $10,0 \mathrm{~cm}$ de altura, quando suas rebrotas alcançaram quatro diferentes alturas $(25$, $50,75 \mathrm{e} 100 \mathrm{~cm}$ ). Os tratamentos de corte foram aplicados em parcelas de $5 \mathrm{~m}$ x $30 \mathrm{~m}$. A avaliação da mortalidade das plantas foi realizada mediante a contagem de todas as plantas mortas e vivas dentro das parcelas experimentais. Os dados foram analisados por intermédio do teste não-paramétrico do qui-quadrado. Verificou-se que houve dependência entre a mortalidade das plantas e o corte das rebrotas e que todos os tratamentos foram diferentes entre si. O melhor resultado foi alcançado quando as rebrotas foram cortadas à altura média de $75 \mathrm{~cm}$, diminuindo a densidade do marmeleiro em até $96 \%$. A redução da densidade proporcionou aumentos significativos na produção de fitomassa herbácea, em relação à área não tratada.
\end{abstract}

Palavras-chave: arbusto, caatinga, controle fisiológico, euphorbiaceae

\section{Effects of the Cutting of Above Ground Parts on Marmeleiro (Croton sonderianus Muell. Arg.) Survival}

\begin{abstract}
The research was conducted at the EMBRAPA - National Center for Goat Research, in Sobral, Ceara, Brazil, to evaluate the effects of cutting of the above ground parts in relation at regrowth height of marmeleiro on its survival, persistence, regrowth vigor and subsequent production of herbaceous understory phytomass. The plants were cut at $10.0 \mathrm{~cm}$ above ground, when the regrowth reached four different heights $(25,50,75$ and $100 \mathrm{~cm})$. The cutting treatments were applied on plots of $5 \mathrm{~m} \times 30 \mathrm{~m}$. The evaluation of the mortality of the plants was accomplished by the count of the total number of dead and alive plants of the experimental plots. Data were analyzed by means of the chi-square nonparametric test. It was observed dependence between mortality of the plants and regrowth cutting, where all treatments were different. Best results were obtained when regrowth plants were cutting to a medium height of $75 \mathrm{~cm}$, which decreased marmeleiro density by $96 \%$. The reduction of density provided a significant increase on herbaceous understory phytomass in relation to control treatment.
\end{abstract}

Key Words: caatinga, control physiology, euphorbiaceae, shrub

\section{Introdução}

O marmeleiro (Croton sonderianus Muell.Arg.) é o principal arbusto colonizador das caatingas sucessionais do Nordeste do Brasil. Esta planta apresenta baixo valor forrageiro e grande poder invasor. Em áreas sucessionais, esta espécie pode apresentar densidade de 10.000 a 45.000 plantas/ha. Com isso, a produção animal por hectare e por ano é muito baixa.

$\mathrm{O}$ aumento da disponibilidade e melhoria da qualidade da forragem da caatinga depende, obrigatoriamente, da manipulação de sua vegetação lenhosa. Com o raleamento da caatinga, a disponibilidade de fitomassa de pé aumenta consideravelmente, atingindo médias anuais de matéria seca que variam de 600 a 4000 kg/ha (ARAÚJO NETO, 1990; SOUZA, 1991; PEREIRAFILHO, 1995; ARAÚJOFILHO et al., 1996).

Os métodos de controle de plantas lenhosas são agrupados em três categorias: físicos, químicos e biológicos. Entre os métodos físicos, têm-se os manuais, os mecânicos e os píricos (VALLENTINE, 1989; ARAÚJO FILHO, 1992). O controle manual, por ser seletivo, talvez seja o mais econômico, quando se deseja controlar plantas lenhosas indesejáveis ou prevenir invasões futuras; dessa forma, a vegetação torna-se adequada ao pastejo animal (HARDESTY, 1981).

\footnotetext{
1 Pesquisa financiada pelo CNPq/Embrapa Caprinos.

2 Prof. Assistente do curso de Zootecnia da Universidade Estadual Vale do Acaraú - UVA, Av. da Universidade 850, 62040-370, Betânia, Sobral, CE, e estudante do curso de Doutorado DZO-UFV. E.mail: fabianno@alunos.ufv.br

3 Pesquisador da Embrapa Caprinos, Bolsista do CNPq, Sobral, CE. E.mail: ambrosio@cnpc.embrapa.br

4 Pesquisador do CNPq, Departamento de Zootecnia da UFV, Viçosa, MG. E.mail: rgarcia@mail.ufv.br

5 Prof. Assistente da UFPB, Patos, PB.

6 Estudante do curso de Zootecnia da UVA, Bolsista do PIBIC-CNPq, Sobral, CE.
} 
Uma revisão de técnicas de manejo de arbustos, usada para todos os trópicos semi-áridos, evidenciou que o vigor da rebrota depois do corte é o principal obstáculo para o controle de arbustos (HOWELL, 1981). Em trabalhos realizados em Quixadá, CE, em área de caatinga sucessional, ficou evidenciado que a aplicação de herbicidas na rebrota de plantas lenhosas indesejáveis, após o desmatamento manual e a ação do fogo, reduziu a densidade destas espécies em 91\% (ARAÚJO FILHO e TORRES, 1982; COUTO et al., 1988). Todavia, a utilização de herbicidas, além de poder causar sérios prejuízos ambientais, apresenta custos que a tornam inacessíveis à grande maioria dos pecuaristas nordestinos.

Por outro lado, o padrão da curva de mobilização dos carboidratos de reserva do marmeleiro, durante a estação chuvosa, revelou que essa espécie apresenta uma curva típica em forma de "U". Isso significa que, seguindo a depleção das reservas, com a rebrota, há um período de cerca de 80 a 100 dias, durante os quais as reservas estão em um ponto crítico, prejudicando a capacidade de recuperação da planta, caso ela tenha sua parte aérea removida (CARVALHO et al., 1998). Essa técnica constitui excelente alternativa de controle do marmeleiro. Todavia, o método necessita de melhor refinamento, principalmente no que tange à época de sua aplicação, com base no crescimento da planta.

O trabalho foi realizado com o objetivo de avaliar os efeitos do corte da parte aérea em relação à altura da rebrota na sobrevivência, persistência e no vigor da rebrota do marmeleiro e na produção subseqüente de fitomassa do estrato herbáceo.

\section{Material e Métodos}

O experimento foi conduzido no período de 1994 a 1996, na Embrapa Caprinos, em Sobral, na zona fisiográfica do Sertão Cearense, a $3^{\circ} 42^{\prime}$ de latitude Sul, $40^{\circ} 21^{\prime}$ de longitude Oeste, à margem da estrada Sobral-Groaíras, km 4, com altitude de 83 metros.

O solo da área experimental é do tipo bruno-nãocálcico vértico, textura argilosa cascalhenta, moderadamente drenado e profundo, fase caatinga hiperxerófila, relevo plano e suave ondulado.

A região possui um clima tipo $\mathrm{BShw}$ ', megatérmico, seco, em que a estação chuvosa (janeiro a junho) apresenta precipitação média de $722 \mathrm{~mm}$, correspondendo a $95,15 \%$ do total médio anual, sendo que $73 \%$ destas ocorrem entre os meses de fevereiro e maio. A temperatura média anual está em torno de $28^{\circ} \mathrm{C}$, sendo as máximas e as mínimas em torno de 35 e $22^{\circ} \mathrm{C}$, respectivamente, e a média da umidade relativa do ar de 69\% (EMBRAPA, 1989). Durante o período de execução do experimento, a precipitação anual na área experimental esteve sempre acima da média histórica e alcançou os totais de 1449,5 mm em 1994; 1141,0 mm em 1995; e 774,8 mm em 1996 (Tabela 1). A temperatura não variou muito ao longo do experimento, tendo distribuições mensais bastante semelhante às médias históricas.

A área experimental é caracterizada por uma vegetação lenhosa, tipo caatinga hiperxerófila, em estádio de sucessão secundária inicial, com uma cobertura de solo de, aproximadamente, $90 \%$, havendo grande predominância do marmeleiro (Croton sonderianus Muell.Arg.), cuja densidade foi, aproximadamente, de 13.684 plantas/ha. Além do marmeleiro, as espécies arbustivo-arbóreas com maior ocorrência na área são: mofumbo (Combretum leprosum Mart.), pau-branco (Auxemma oncocalyx

Tabela 1 - Precipitação pluvial (mm) ocorrida na Embrapa Caprinos, no período de 1994 a 1996, Sobral, Ceará

Table 1 - Rainfall at the Embrapa Caprinos from 1994 to 1996, Sobral, Ceará

\begin{tabular}{lccc}
\hline $\begin{array}{l}\text { Mês } \\
\text { Month }\end{array}$ & \multicolumn{3}{c}{$\begin{array}{c}\text { Ano } \\
\text { Year }\end{array}$} \\
\cline { 2 - 4 } & 1994 & 1995 & 1996 \\
\hline $\begin{array}{l}\text { Janeiro } \\
\text { January }\end{array}$ & 120,5 & 118,0 & 55,0 \\
$\begin{array}{l}\text { Fevereiro } \\
\text { February }\end{array}$ & 280,0 & 174,0 & 91,0 \\
$\begin{array}{l}\text { Março } \\
\text { March }\end{array}$ & 239,0 & 212,0 & 242,8 \\
$\begin{array}{l}\text { Abril } \\
\text { April }\end{array}$ & 506,0 & 322,0 & 314,0 \\
$\begin{array}{l}\text { Maio } \\
\text { May }\end{array}$ & 118,0 & 289,0 & 72,0 \\
$\begin{array}{l}\text { Junho } \\
\text { June }\end{array}$ & 186,0 & 26,0 & - \\
$\begin{array}{l}\text { Julho } \\
\text { July }\end{array}$ & - & - & - \\
$\begin{array}{l}\text { Agosto } \\
\text { August } \\
\text { Setembro } \\
\text { September }\end{array}$ & - & - & - \\
$\begin{array}{l}\text { Outubro } \\
\text { October }\end{array}$ & - & - & - \\
$\begin{array}{l}\text { Novembro } \\
\text { November }\end{array}$ & - & - & - \\
$\begin{array}{l}\text { Dezembro } \\
\text { December } \\
\text { Total }\end{array}$ & - & & - \\
\hline
\end{tabular}


932 Rev. bras. zootec.

Taub.), catingueira (Caesalpinia bracteosa Tul.), jucazeiro (Caesalpinia ferrea Mart.), sabiá (Mimosa caesalpiniifolia Benth.) e jurema-preta (Mimosa tenuiflora (Willd.) Poir.). O estrato herbáceo, apesar de escasso, era composto principalmente por espécies anuais, destacando-se o capim-panasco (Aristidia setifolia H.B.K.), o bamburral (Hyptis suaveolens Poit.), a malva relógio (Sida spp.), o mata-pasto (Senna obtusifolia L.), a vassourinha de botão (Borreria verticillata G.F.W.Mayer), a erva de ovelha (Stylosanthes humilis H.B.K.), o capimmilhã (Brachiaria spp.; Panicum spp.; Setaria spp.), entre outras. A maioria das espécies lenhosas perde inteiramente as folhas, a partir do início da estação seca.

Uma área de $25 \times 30 \mathrm{~m}$ foi subdividida em cinco parcelas de $5 \times 30 \mathrm{~m}$ cada, nas quais se aplicaram os tratamentos: testemunha - sem corte da parte aérea; $\mathrm{T}-25$ - corte quando as rebrotas alcançaram $25 \mathrm{~cm}$; $\mathrm{T}-50$ - corte quando as rebrotas alcançaram $50 \mathrm{~cm}$; $\mathrm{T}-75$ - corte quando as rebrotas alcançaram $75 \mathrm{~cm}$; e T-100 - corte quando as rebrotas alcançaram $100 \mathrm{~cm}$. Todas as plantas das parcelas foram cortadas à altura aproximada de $10,0 \mathrm{~cm}$.

Os tratamentos, exceto a testemunha, receberam um corte de uniformização no período seco, no início do trabalho (dezembro de 1993), um primeiro corte quando as rebrotas atingiram as alturas acima descritas (fevereiro/março) e um segundo corte ao final de cada estação chuvosa, sempre no mês de junho, no período de 1994 a 1996, independente da altura das rebrotas.

Cada tratamento era constituído de uma única parcela experimental e a avaliação da mortalidade das plantas foi realizada mediante a contagem de todas as plantas mortas e vivas dentro de cada parcela, sempre no período chuvoso, e os resultados foram expressos por hectare.

Para quantificação da matéria seca do estrato herbáceo, foi utilizada uma moldura de ferro chato, de 0,25 m x 1,0 m (ARAÚJO FILHO et. al., 1986), distribuída ao acaso dentro de cada parcela experimental. Dentro de cada parcela experimental, foram realizadas cinco amostragens, sendo os valores médios expressos por hectare. Os componentes do estrato herbáceo foram separados em gramíneas e dicotiledôneas herbáceas, cortados rente ao solo, colocados em sacos plásticos e pesados. Ao final de cada coleta, foi feita uma amostra composta para cada grupo de espécie, levada para uma estufa de circulação forçada de ar, graduada em $65^{\circ} \mathrm{C}$, por 48 horas, para a obtenção do peso do material pré-seco.

Os dados foram colocados em tabelas de distri- buição de freqüências e analisados pelo teste nãoparamétrico, teste do qui-quadrado (CONOVER, 1971; CAMPOS, 1983; GOMES, 1990).

\section{Resultados e Discussão}

A densidade do marmeleiro, por ocasião do corte de uniformização (1993), variou de 15.134 plantas/ha, no tratamento T-75, ao mínimo de $12.550 \mathrm{plantas} / \mathrm{ha}$, no testemunha (Figura 1). No tratamento testemunha, a densidade do marmeleiro apresentou ligeira diminuição, ao longo do período experimental, porém sob o efeito dos tratamentos de corte houve notável decréscimo deste parâmetro nas parcelas experimentais. Este resultado foi particularmente visível no tratamento T-75.

Na análise do teste do qui-quadrado, por intermédio da tabela de contingência, observou-se que as freqüências esperadas das mortalidades foram sempre inferiores às observadas em todos os tratamentos, em que se procedeu ao corte da parte aérea, o que mostra a maior eficiência destes tratamentos em relação ao testemunha. Os resultados obtidos pelo teste do qui-quadrado foram significativos $(p<0,01)$, indicando que o corte da rebrota na época chuvosa é eficiente no controle do marmeleiro (Tabela 2 e Figura 2).

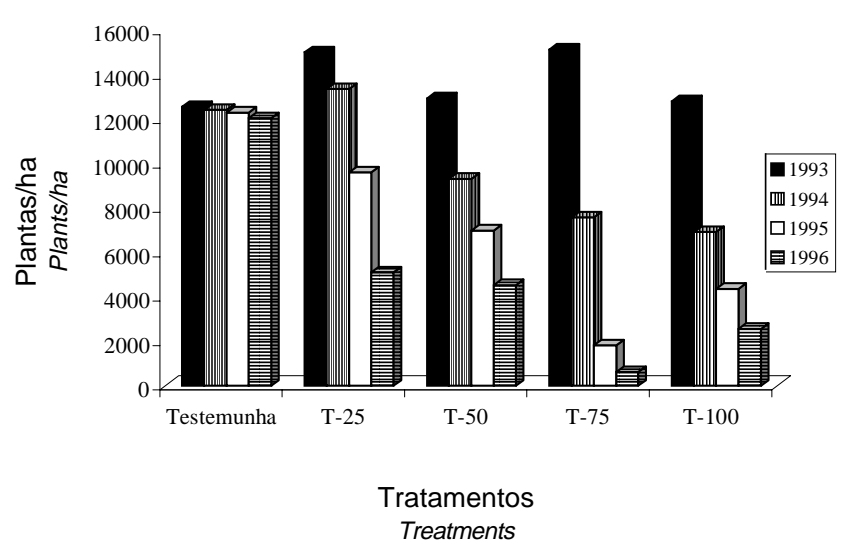

Figura 1 - Número de plantas de marmeleiro (Croton sonderianus) por hectare, por ocasião do corte de uniformização (1993) e no período de 1994 a 1996, em função dos tratamentos, Sobral, Ceará.

Figure 1 - Number of marmeleiro plants (Croton sonderianus) per hectare, at the standardization cut (1993) and from 1994 to 1996, according to treatments, Sobral, Ceará. 
CARVALHO et al.

Tabela 2 - Número de plantas de marmeleiro (Croton sonderianus) por hectare, por ocasião do corte de uniformização (1993), freqüências observadas e porcentagem de plantas mortas, em função dos tratamentos, no período de 1994 a 1996, Sobral, Ceará

Table 2 - Number of marmeleiro plants (Croton sonderianus) per hectare, at the standartization cut (1993), observed frequencies and percentage of dead plants, according to treatments, from 1994 to 1996, Sobral, Ceará

\begin{tabular}{lccrc}
\hline $\begin{array}{l}\text { Tratamento } \\
\text { Treatment }\end{array}$ & $\begin{array}{c}\mathrm{N}^{\mathrm{O}} \text { inicial de plantas } \\
\text { Initial number of plants }\end{array}$ & \multicolumn{2}{c}{$\begin{array}{c}\text { Freqüência observada } \\
\text { Observed frequency }\end{array}$} & $\begin{array}{c}\text { \% Mortos } \\
\text { \% Dead }\end{array}$ \\
\cline { 3 - 4 } & & $\begin{array}{c}\text { Mortos } \\
\text { Dead }\end{array}$ & $\begin{array}{c}\text { Vivos } \\
\text { Alive }\end{array}$ & \\
\hline $\begin{array}{l}\text { Testemunha } \\
\text { Control }\end{array}$ & 12550 & 502 & 12048 & 4,0 \\
T-25 & & & & \\
T-50 & 15000 & 9900 & 5100 & 66,0 \\
T-75 & 12934 & 8666 & 4268 & 67,0 \\
T-100 & 15134 & 14529 & 605 & 96,0 \\
& 12800 & 10240 & 2560 & 80,0 \\
\hline
\end{tabular}

O corte da parte aérea mostrou-se bastante eficiente, como prática de controle do marmeleiro, com resultados satisfatórios para todos os tratamentos, em relação ao testemunha, que apresentou mortalidade de apenas $4 \%$. Todos os tratamentos diferiram $(\mathrm{p}<0,01)$ entre si, sendo observado melhor resultado quando da realização do corte em rebrotas que atingiram $75 \mathrm{~cm}$ de altura, com mortalidade de 96\% (Tabela 2 e Figura 2). Estes resultados são comparáveis aos obtidos por ARAÚJO FILHO e TORRES (1982), quando, com o uso de arbusticida,

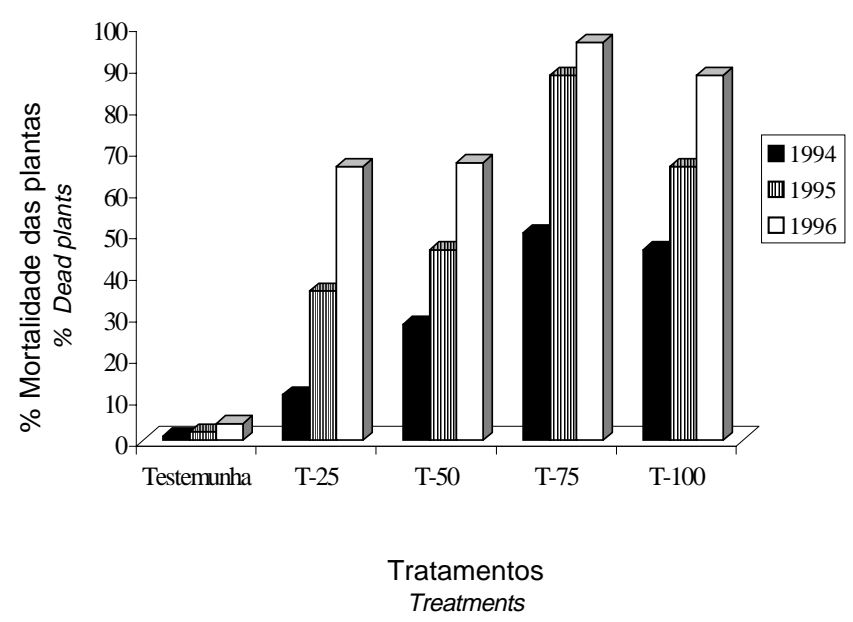

Figura 2 - Porcentagem de mortalidade de plantas de marmeleiro (Croton sonderianus) por hectare, nos tratamentos, nos anos de 1994 a1996, Sobral, Ceará.

Figure 2 - Percentage of mortality of marmeleiro plants (Croton sonderianus) per hectare, in the treatments, from 1994 to 1996, Sobral, Ceará. obteve-se controle de $91 \%$ para espécies lenhosas da caatinga.

Os tratamentos em que o corte foi realizado quando as rebrotas atingiram 25 e $50 \mathrm{~cm}$ de altura, foram os que causaram menor mortalidade, devido, provavelmente, ao maior intervalo da aplicação ao primeiro (fevereiro) e segundo cortes (junho), o que favoreceu maiores percentuais de carboidratos de reserva no início da estação seca (T-25 - 11,19\% e T-50 $11,35 \%)$, propiciando melhores condições de sobrevivência no período seco seguinte (CARVALHO et al., 2000). Já os tratamentos em que o corte foi realizado quando as rebrotas atingiram 75 e $100 \mathrm{~cm}$ foram os que causaram maior mortalidade, justificado, aparentemente, pelo menor intervalo da aplicação ao primeiro (março) e segundo cortes (junho), o que não permitiu às plantas a plena reposição dos percentuais das reservas orgânicas no início do período seco (T-75 - 8,45\% e T-100 - 9,47\%), para enfrentarem a estação seca seguinte (CARVALHO et al., 2000). Além desses fatores, CARVALHO et al. (1998) ressaltaram que o corte da parte aérea ocasiona grande estresse fisiológico e, por conseguinte, elevada mortalidade, o que justifica a aplicação do corte da rebrota como medida eficiente de controle, no período chuvoso.

$\mathrm{O}$ controle das rebrotas do marmeleiro acarretou incrementos substanciais na disponibilidade de fitomassa do estrato herbáceo. Enquanto na área testemunha a produção média de fitomassa de pé foi de $527,61 \mathrm{~kg}$ de MS/ha, nas áreas tratadas variou de $3.932,33$, no trata- 
934 Rev. bras. zootec.

mento T-75, a 4.930,11 kg de MS/ha, no tratamento T-25 (Tabela 3). Mais uma vez, os tratamentos T-25 e $\mathrm{T}-50$ tenderam à maior produção de fitomassa do estrato herbáceo, por permitirem mais tempo para o desenvolvimento das plantas herbáceas que os demais.

Tabela 3 - Produção de fitomassa de pé (gramíneas + dicotiledôneas herbáceas) em $\mathrm{kg} / \mathrm{ha}$ de MS, nos tratamentos, no período de 1994 a 1996, Sobral, Ceará

Table 3 - Production of aerial phytomass (grasses + forbs) in $\mathrm{kg} / \mathrm{ha}$ of DM in the treatments, from 1994 to 1996, Sobral, Ceará

\begin{tabular}{lcccc}
\hline $\begin{array}{l}\text { Tratamentos } \\
\text { Treatments }\end{array}$ & \multicolumn{3}{c}{$\begin{array}{c}\text { Anos } \\
\text { Years }\end{array}$} & \multirow{2}{*}{$\begin{array}{l}\text { Média } \\
\text { Means }\end{array}$} \\
\cline { 2 - 4 } & 1994 & 1995 & 1996 & \\
\hline Testemunha & 578,56 & 547,56 & 456,72 & 527,61 \\
Control & & & & \\
T-25 & 4741,52 & 5734,00 & 4314,80 & 4930,11 \\
T-50 & 5003,36 & 4510,64 & 4611,00 & 4708,33 \\
T-75 & 3734,48 & 3819,28 & 4243,22 & 3932,33 \\
T-100 & 5478,72 & 3605,52 & 4392,12 & 4492,12 \\
\hline
\end{tabular}

\section{Conclusões}

O controle do marmeleiro, por intermédio do corte da parte aérea, deve ser feito na estação úmida, quando suas rebrotas atingirem $75 \mathrm{~cm}$ de altura.

Esta técnica de controle reduziu a densidade do marmeleiro em até $96 \%$, mostrando-se bastante eficiente e não-poluente do ambiente, devendo ser indicada para o controle do marmeleiro no Sertão Nordestino.

A produção de fitomassa de pé, nas áreas tratadas, aumentou em 7 a 9 vezes em relação à área nãotratada, favorecendo, assim, o aumento da capacidade de suporte.

\section{Referências Bibliográficas}

ARAÚJO FILHO, J.A. 1992. Manipulação da vegetação lenhosa da caatinga para fins pastoris. Sobral, CE: EMBRAPACNPC. 18p. (EMBRAPA-CNPC. Circular Técnica, 11).

ARAÚJO FILHO, J.A., GADELHA, J.A., LEITE, E.R. et al. 1996. Composição botânica e química da dieta de ovinos e caprinos em pastoreio combinado na região dos Inhamuns, Ceará. R. Soc. Bras. Zootec., 25(3):383-395.

ARAÚJO FILHO, J.A., TORRES, S.M. 1982. Controle de plantas lenhosas indesejáveis em pastagens nativas dos sertões cearenses. In: UNIVERSIDADE FEDERAL DO CEARÁ. Estudos de pastagem nativa do Ceará. Fortaleza, CE: UFC/ BNB. p.11-31 (BNB. Estudos Econômicos e Sociais, 13).
ARAÚJO FILHO, J.A., VALE, L.V., ARAÚJO NETO, R.B. et al. Dimensões de parcelas para amostragem do estrato herbáceo da caatinga raleada. In: REUNIÃO ANUAL DA SOCIEDADE BRASILEIRA DE ZOOTECNIA, 23, 1986, Campo Grande. Anais.... Campo Grande, MS: SBZ, 1986. p. 268 .

ARAÚJO NETO, R.B. Efeito do pastejo por ovinos sobre a composiçãoflorística da vegetação herbáce a de uma caatinga raleada. Fortaleza, CE: UFC, 1990.106p. Dissertação (Mestrado em Zootecnia) - Universidade Federal do Ceará, 1990.

CAMPOS, H. 1983. Estatística experimental não-paramétrica. Piracicaba, SP: Nobel. 332p.

CARVALHO, F.C., ARAÚJO FILHO, J.A., RÊGO, M.C. et al. 1998. Flutuações dos níveis dos carboidratos de reserva disponíveis nas raízes e no caule do marmeleiro (Croton sonderianus Muell.Arg.), ao longo dos diferentes estádios fenológicos. R. Soc. Bras. Zootec., 23(1):670-675.

CARVALHO, F.C., ARAÚJO FILHO, J.A., GARCIA, R. et al. Efeito do corte da parte aérea sobre as mobilizações dos carboidratos de reserva nas raízes do marmeleiro (Croton sonderianus Muell.Arg.). In: REUNIÃO ANUAL DA SOCIEDADE BRASILEIRA DE ZOOTECNIA, 37, 2000, Viçosa. Anais... Viçosa, MG: SBZ, 2000. (CD -ROM).

CONOVER, W.J. 1971. Pratical nonparametric statistics. New York: John Wiley. 568p.

COUTO, D.S., MOREIRA, J.O., ARAÚJO FILHO, J.A. 1988. Métodos de controle de espécies lenhosas indesejáveis em quatro sítios ecológicos dos sertões do Ceará. Fortaleza, CE: EPACE. 33p. (EPACE. Boletim de Pesquisa, 12).

EMPRESA BRASILEIRA DE PESQUISA E AGROPECUÁRIA EMBRAPA. 1989. Relatório técnico anual do Centro Nacional de Pesquisa de Caprinos 1982-1986. Sobral, CE: EMBRAPA-CNPC. $284 \mathrm{p}$.

GOMES, F.P. 1990. Curso de estatística experimental. Piracicaba, SP: Nobel. 469p.

HARDESTY, L.H. 1981. Brush management on semi-arid tropical rangelands: implications for improved caatinga management. Sobral, CE: EMBRAPA-CNPC/SR-CRSP. 35p.

HOWELL, L.A. A rewiew of tropical and subtropical brush management techiques with special reference to northeast Brazil. Logan, EUA: Utha State University, 1981. 185p (Thesis - Doctor) - Utha State University, 1981.

PEREIRA FILHO, J.M. Efeitos do pastoreio alternado ovinocaprino sobre a composição florística da vegetação herbácea de uma caatinga raleada. Fortaleza, CE: UFC, 1995. 86p. Dissertação (Mestrado em Zootecnia) - Universidade Federal do Ceará, 1995.

SOUSA, P.Z. Flutuações estacionais da dieta de ovinos e caprinos em pastoreio combinado na região dos Inhamuns, Ceará. Fortaleza, CE: UFC, 1991. 98p. Dissertação (Mestrado em Zootecnia) - Universidade Federal do Ceará, 1991.

VALLENTINE, J.F. 1989. Range development and improvement. Provo, EUA: Brigham Young University Press. 535p.

Recebido em: 03/03/00

Aceito em: 02/03/01 